\title{
Hypoxia alters the recruitment of tropomyosins into the actin stress fibres of neuroblastoma cells
}

\author{
Joshua J. Glass ${ }^{1,3}$, Phoebe A. Phillips², Peter W. Gunning ${ }^{1 *}$ and Justine R. Stehn ${ }^{1}$
}

\begin{abstract}
Background: Neuroblastoma is the most common extracranial solid tumor of childhood. The heterogeneous microenvironment of solid tumors contains hypoxic regions associated with poor prognosis and chemoresistance. Hypoxia implicates the actin cytoskeleton through its essential roles in motility, invasion and proliferation. However, hypoxia-induced changes in the actin cytoskeleton have only recently been observed in human cells. Tropomyosins are key regulators of the actin cytoskeleton and we hypothesized that tropomyosins may mediate hypoxic phenotypes.

Methods: Neuroblastoma (SH-EP) cells were incubated \pm hypoxia $\left(1 \% \mathrm{O}_{2}, 5 \% \mathrm{CO}_{2}\right)$ for up to $144 \mathrm{~h}$, before examining the cytoskeleton by confocal microscopy and Western blotting.

Results: Hypoxic cells were characterized by a more organized actin cytoskeleton and a reduced ability to degrade gelatin substrates. Hypoxia significantly increased mean actin filament bundle width (72 h) and actin filament length (72-96 h). This correlated with increased hypoxic expression and filamentous organization of stabilizing tropomyosins Tm1 and Tm2. However, isoform specific changes in tropomyosin expression were more evident at $96 \mathrm{~h}$.

Conclusions: This study demonstrates hypoxia-induced changes in the recruitment of high molecular weight tropomyosins into the actin stress fibres of a human cancer. While hypoxia induced clear changes in actin organization compared with parallel normoxic cultures of neuroblastoma, the precise role of tropomyosins in this hypoxic actin reorganization remains to be determined.
\end{abstract}

Keywords: Hypoxia, Actin, Tropomyosin, Neuroblastoma

\section{Background}

Neuroblastoma is the most common extracranial solid tumor of childhood. These neoplasms derive from immature cells of the sympathetic nervous system (SNS) and can present at any SNS structure, most commonly in and around the adrenal glands [1,2]. Over $90 \%$ of patients are younger than 5 years at diagnosis and over half present with metastatic spread, predominately to the bone marrow and bone [3, 4]. While overall survival for stage 1 and 2 patients is $96.2 \%$ and $88.6 \%$, respectively, overall survival for high-grade, stage 4 patients remains low at $22.4 \%$ [5].

Solid tumors are heterogeneous, complex structures that must be analysed in the context of their microenvironment [6]. Structurally and functionally poor quality tumor vasculature leads to regions of low oxygen $\left(\mathrm{O}_{2}\right)$ perfusion referred to as hypoxia [7]. Prognoses are made worse by hypoxic

\footnotetext{
* Correspondence: p.gunning@unsw.edu.au

'Oncology Research Unit, School of Medical Sciences, UNSW Australia, Room 229, Wallace Wurth Building, Sydney, NSW 2052, Australia

Full list of author information is available at the end of the article
}

microenvironments, which create genetic instability fundamental to tumor progression [8] and increase neuroblastoma resistance to radiotherapy and standard chemotherapies [9-12]. The actin cytoskeleton is essential for various hypoxic phenotypes, including altered motility and invasion. However, until now, no studies have examined the effect of hypoxia on the actin cytoskeleton of neuroblastoma.

The aggressive hypoxic phenotype of neuroblastoma is well documented. Over a decade ago, Ginis and Faller [13] observed that Kelly neuroblastoma cells increased their invasiveness and decreased their adhesion to endothelium when treated to hypoxic conditions, indicating a prometastatic phenotype. Hypoxia-fostered malignancies are worsened by neuroblastoma dedifferentiation in vitro and in vivo, with reversion to an immature and neural crest-like phenotype [14]. Such dedifferentiation is associated with increased tumor heterogeneity and aggressiveness [14, 15]. Moreover, the neuroblastoma transcriptome and proteome are dramatically altered by hypoxia toward malignant and 
metastatic profiles. Hypoxia upregulates the expression of genes associated with growth, survival and drug resistance [16] and induces a pro-metastatic gene program [17].

Hypoxia-inducible factor (HIF) transcription factors are believed to be the master transcriptional regulators of the hypoxic response [18, 19]. HIFs are heterodimeric transcription factors composed of an $\mathrm{O}_{2}$-regulated $\alpha$ subunit and a constitutively expressed $\beta$ subunit [20]. Under conventional tissue culture $\mathrm{O}_{2}$ tensions $\left(20 \% \mathrm{O}_{2}\right)$, referred to as normoxia, HIF- $\alpha$ subunits are rapidly hydroxylated, ubiquitinated and proteasomally degraded [21-23]. At $1 \% \mathrm{O}_{2}$, HIF- $1 \alpha$ and HIF- $2 \alpha$ subunits are stabilized and translocate to the nucleus [24]. Whether caused by hypoxia or oncogenic mutations, increased HIF levels are largely associated with poor prognoses in a variety of cancers [18]. In neuroblastoma, HIF- $2 \alpha$ predicts poor patient outcome, while HIF- $1 \alpha$ has been associated with a favorable prognosis [25]. Intriguingly, hypoxia-induced chemoresistance is HIF-1 $\alpha-$ dependent $[11,12]$. More recently, the sonic hedgehog signaling pathway has been implicated in HIF- $1 \alpha$-mediated proliferation and invasion of neuroblastoma cells [26].

Actin is a core component of the eukaryotic cytoskeleton. It is well established that changes in actin organization and the levels of its binding proteins are essential to the cancer cell phenotype (reviewed in $[27,28]$ ). In fact, the actin cytoskeleton is essential for a variety of processes hijacked or subverted by hypoxic cancer cells. These include proliferation, invasion, motility, adhesion and apoptosis [28-32]. A recent study found that hypoxia led to HIF-1 $\alpha$-dependent actin filament rearrangement in mouse L929 fibrosarcoma cells [33]. However, to our knowledge, no studies have previously examined the role of the actin cytoskeleton in hypoxic human cancer phenotypes.

The tropomyosin family of proteins are involved in most, if not all, actin cytoskeletal functions [34]. Tropomyosins exist as rod-like coiled coil dimers that form head-to-tail polymers [35] and wrap along the major grooves of most actin filaments. Four genes, TPM1-4, encode over 40 mammalian isoforms through splicing and alternative promoters. High (HMW) and low molecular weight (LMW) isoforms correspond to $\sim 284$ and 247 amino acids, respectively [36]. Tropomyosins contribute to the spatial and temporal regulation of the actin cytoskeleton in an isoform-specific manner, by regulating actin's association with a plethora of actinbinding proteins [34]. Interestingly, tropomyosins are implicated in the pathogenesis of cancer. HMW isoforms are consistently down-regulated in transformed cells, while malignant cells display an increased reliance on LMW isoforms [37]. We have previously observed consistent down-regulation of HMW isoforms (Tm1, Tm2 and Tm3) and an increased reliance on LMW isoforms (Tm5NM1/2 and Tm4) in all profiled neuroblastoma and melanoma cell lines, as well as transformed primary BJ fibroblasts [38].

We hypothesized that tropomyosins may facilitate the hypoxic phenotypes of cancers such as neuroblastoma by driving changes in the actin cytoskeleton. We therefore aimed (1) to characterize the hypoxic phenotype by observing changes in neuroblastoma cell proliferation and invasion, and (2) to examine hypoxia-induced changes in the actin cytoskeleton, including tropomyosin isoform expression and localization.

In this study we have demonstrated hypoxia-induced changes in tropomyosin expression and localization in a human cancer. Changes in actin organization characteristic of reversion of the transformed phenotype are induced by hypoxia at $72 \mathrm{~h}$ in neuroblastoma. This correlates with expected isoform-specific changes in tropomyosin localization. However, isoform specific changes in tropomyosin expression are more evident at $96 \mathrm{~h}$. Hypoxia induces clear changes in actin organization compared with parallel normoxic cultures of neuroblastoma. However, the role tropomyosins might play in driving this hypoxic actin reorganization remains to be further elucidated.

\section{Methods}

\section{Cell culture}

SK-N-SH-EP (SH-EP) human neuroblastoma cells [39, 40] were a generous gift from Children's Hospital Westmead. STR fingerprinting was performed to confirm the cell line's identity. SH-EP were maintained in growth media containing Dulbecco's modified Eagle's medium (DMEM)/ high glucose $(4.5 \mathrm{~g} / \mathrm{L})$, L-glutamine $(4.0 \mathrm{mM})$ and sodium pyruvate $(4.0 \mathrm{mM})$ (HyClone-Thermo Scientific, UT, USA), supplemented with $10 \% \mathrm{v} / \mathrm{v}$ fetal bovine serum (FBS) (Gibco-Life Technologies, NY, USA). Cells maintained at $37{ }^{\circ} \mathrm{C}$ in humidified, normoxic $5 \% \mathrm{CO}_{2} / 95 \%$ air incubator $\left(\sim 20 \% \mathrm{O}_{2}\right)$. All replicate experiments conducted within 6 passages. All studies reported in this manuscript were in vitro cell based studies using human cancer cell lines that are commercially available.

\section{Hypoxic incubation}

In neuroblastoma, metabolic hypoxia occurs below 8-10 mmHg $\mathrm{O}_{2}$ (approx. 1.1-1.3\% $\mathrm{O}_{2}$ ) [41]. To induce hypoxia, cells were placed inside a modular incubator chamber (Billups-Rothenberg, CA, USA) and flushed with $1 \% \mathrm{O}_{2} / 5 \% \mathrm{CO}_{2} / 94 \% \mathrm{~N}_{2}$ gas (BOC Australia, NSW, AUS) for $8 \mathrm{mins}$ at $25 \mathrm{~L} / \mathrm{min}$. The sealed chamber was incubated at $37^{\circ} \mathrm{C}$ and flushing was repeated every $24 \mathrm{~h}$.

\section{Cell proliferation}

Cells were seeded in $100 \mathrm{~mm}$ plates (Costar-Corning, NY, USA) at $9.2 \times 10^{4} / 10 \mathrm{~mL}$ media and incubated at $37^{\circ} \mathrm{C}$ overnight, before incubating \pm hypoxia for $24-144 \mathrm{~h}$. Cells were harvested with trypsin-EDTA (Gibco-Life 
Technologies, NY, USA) and resuspended in growth media. Live cells counted using Countess ${ }^{\circ}$ Automated Cell Counter after mixing 1:1 with $0.4 \%$ w/v trypan blue (Invitrogen, CA, USA).

\section{Invasion assays}

QCM Gelatin Invadopodia Assay (Millipore, MA, USA) performed as per manufacturer's instructions in 8-well Lab-Tek ${ }^{\bullet}$ chamber slides (Nunc, IL, USA). Briefly, cells seeded at $1.6 \times 10^{4} /$ well onto GFP-tagged gelatin to examine invadopodial matrix-degradation. After 72-96 h \pm hypoxia, cells were fixed and stained with kit-supplied DAPI nucleic acid stain and filamentous actin-binding TRITC-phalloidin. Coverslips mounted with ProLong Gold Antifade Reagent (Invitrogen, OR, USA) and cells visualized using an Axioskop 40 epifluorescent microscope (20× objective) (Zeiss, Göttingen, Germany). Five fields of view obtained per condition. Gelatin degradation, cell area and cell counts quantified using ImageJ (V1.46; NIH).

\section{Actin cytoskeleton and tropomyosin organization}

Cells seeded at $9.2 \times 10^{3} / \mathrm{mL}$ media on coverslips (Carl Zeiss Microscopy, NY, USA) and incubated overnight in normoxia. Cells then incubated \pm hypoxia for $48-96 \mathrm{~h}$ (actin cytoskeleton) or $72 \mathrm{~h}$ (tropomyosin). Cells fixed in $4 \% \mathrm{w} / \mathrm{v}$ paraformaldehyde (PFA) in phosphate-buffered saline (PBS) for 15 mins, then washed thrice in PBS. All staining performed at room temperature (RT), as below.

\section{Actin and tropomyosin immunofluorescence staining}

For actin filament staining, cells were permeabilized with $0.1 \% \mathrm{v} / \mathrm{v}$ TritonX-100 for 5 mins, washed thrice in PBS, blocked in $0.5 \% \mathrm{w} / \mathrm{v}$ bovine serum albumin (BSA) in PBS for $1 \mathrm{~h}$, incubated with TRITC-phalloidin (1:1,000; Sigma-Aldrich) in $0.5 \% \mathrm{w} / \mathrm{v}$ BSA and washed thrice in PBS. For anti-tropomyosin staining, cells were permeabilized with $-80{ }^{\circ} \mathrm{C}$ methanol for 15 mins, washed thrice in PBS, blocked with $2 \% \mathrm{v} / \mathrm{v}$ FBS in PBS for 30 mins, incubated with primary tropomyosin isoformspecific antibody for $2 \mathrm{~h}$ diluted in $2 \% \mathrm{v} / \mathrm{v}$ FBS as per Table 1, washed thrice in PBS, incubated with appropriate Alexa555- or Alexa488-conjugated secondary antibody for $1 \mathrm{~h}$ in the dark, diluted in $2 \% \mathrm{v} / \mathrm{v}$ FBS as per Table 1, and washed thrice in PBS. All coverslips then incubated with DAPI nucleic acid stain $(1: 10,000)$ in PBS for $1 \mathrm{~min}$, washed thrice in PBS and mounted onto microscope slides using ProLong Gold Antifade Reagent.

Single z-plane images obtained using an SP5 2P STED confocal microscope (40× oil objective) (Leica Microsystems, Wetzlar, Germany). Actin filament bundle width and length were quantitated using a linear-feature detection algorithm developed in collaboration with the CSIRO and previously described [42].

Table 1 Primary and secondary antibodies

\begin{tabular}{|c|c|c|c|c|c|c|}
\hline Name & $1^{\circ} / 2^{\circ}$ & Target & Dilution & Species & Commercial availability & Ref. \\
\hline$a / 9 d$ & $1^{\circ}$ & $\operatorname{Tm} 1,2,3,5 a^{*}, 5 b^{*}, 6^{*}$ & WB/F: 1:500 & $\begin{array}{l}\text { Mouse monoclonal (lgG2b K; } \\
\text { clone 15D12.2 }\end{array}$ & - & [79] \\
\hline$\gamma / 9 d$ & $1^{\circ}$ & Tm5NM1/2 & WB/IF: 1:500 & $\begin{array}{l}\text { Mouse monoclonal (lgG2b k; } \\
\text { clone 2G10.2) }\end{array}$ & - & [79] \\
\hline WD4/9d & $1^{\circ}$ & Tm4 & WB/IF: 1:500 & Rabbit polyclonal & Millipore & {$[80]$} \\
\hline CG1 & $1^{\circ}$ & Tm1 & IF: $1: 50$ & Mouse monoclonal (lgG) & - & [79] \\
\hline CG3 & $1^{\circ}$ & Tm5NM1-11 & WB/F: 1:150 & Mouse monoclonal (IgM) & - & [79] \\
\hline CGß6 & $1^{\circ}$ & $\operatorname{Tm} 2,3$ & IF: 1:150 & Mouse monoclonal (lgM) & - & [79] \\
\hline $\operatorname{Tm} 311$ & $1^{\circ}$ & $\operatorname{Tm} 1,2,3,6^{*}, \mathrm{Br} 1^{*}$, plus $\mathrm{a}-, \beta-$, -muscle $^{*}$ & IF: 1:500 & $\begin{array}{l}\text { Mouse monoclonal (|gG1), } \\
\text { clone TM311 }\end{array}$ & Sigma-Aldrich & [81] \\
\hline C4 Actin & $1^{\circ}$ & Actin & WB: 1:5000 & $\begin{array}{l}\text { Mouse monoclonal, (lgG1k; } \\
\text { clone } C 4 \text { ) }\end{array}$ & Millipore & [82] \\
\hline a-actinin & $1^{\circ}$ & a-actinin 1-4 & WB: 1:200 & Rabbit polyclonal $(\mathrm{H}-300)$ & Santa Cruz Biotechnology & [83] \\
\hline HIF-1a & $1^{\circ}$ & HIF-1a & WB: $1: 500$ & $\begin{array}{l}\text { Mouse monoclonal (IgG1; } \\
\text { clone 54) }\end{array}$ & BD Biosciences & [20] \\
\hline HIF-2a & $1^{\circ}$ & $\mathrm{HIF}-2 \mathrm{a}$ & WB: $1: 500$ & Rabbit polyclonal & Novus Biologicals & [84] \\
\hline GAM-HRP & $2^{\circ}$ & Mouse $(H+L)$ & WB: 1:5000 & Goat polyclonal & Bio-Rad & [85] \\
\hline GAR-HRP & $2^{\circ}$ & Rabbit $(\mathrm{H}+\mathrm{L})$ & WB: 1:5000 & Goat polyclonal & Bio-Rad & [85] \\
\hline Alexa Fluor 555 GAM & $2^{\circ}$ & Mouse $(H+L)$ & IF: 1:1000 & Goat polyclonal & Molecular Probes & [86] \\
\hline Alexa Fluor ${ }^{\oplus} 88$ GAR & $2^{\circ}$ & Rabbit $(\mathrm{H}+\mathrm{L})$ & IF: 1:1000 & Goat polyclonal & Molecular Probes & [86] \\
\hline
\end{tabular}

*Tropomyosin isoforms not expressed by SH-EP (Stehn et al., unpublished data). Those antibodies not commercially available were generated in-house WB Western blot, IF immunofluorescence, $1^{\circ}$ primary antibody, $2^{\circ}$ secondary antibody, GAM goat anti-mouse, GAR goat anti-rabbit, $H R P$ horseradish peroxidase, $H$ heavy chain of lgG, $L$ light chain of $\lg G$ 


\section{Protein expression analysis}

Cells were seeded in $100 \mathrm{~mm}$ plates at $9.2 \times 10^{4} / 10 \mathrm{~mL}$, incubated overnight in normoxia at $37{ }^{\circ} \mathrm{C}$, before incubating \pm hypoxia for $48-144 \mathrm{~h}$. Cells were harvested using trypsin-EDTA, pelleted by centrifugation $\left(1,200 \mathrm{rpm}, 4{ }^{\circ} \mathrm{C}, 10 \mathrm{mins}\right)$ and stored at $-80{ }^{\circ} \mathrm{C}$ unless used immediately. Cells lysed in $100 \mu \mathrm{l} / 4 \times 10^{5}$ cells of radioimmunoprecipitation assay (RIPA) buffer $(6.67 \mathrm{~mL}$ $1.5 \mathrm{M}$ Tris pH 8.0, $2 \mathrm{~mL}$ NP-40, 1 g deoxycholic acid, $1 \mathrm{~mL} 20 \% \mathrm{w} / \mathrm{v}$ SDS, $1.752 \mathrm{~g} \mathrm{NaCl}$ made to $200 \mathrm{~mL}$ with $\mathrm{ddH}_{2} \mathrm{O}$ ) containing complete protease inhibitor cocktail (Roche Applied Science, IN, USA). For HIF-1/2 $\alpha$ immunoblots, plates were transferred immediately to ice, rinsed with ice-cold PBS containing complete protease inhibitor cocktail and mechanically scraped using 50-100 $\mu$ l RIPA buffer containing protease inhibitor cocktail. All lysates incubated on ice for 20 mins before centrifugation $\left(16,100 \times \mathrm{g}, 4{ }^{\circ} \mathrm{C}, 10 \mathrm{mins}\right)$. Supernatants transferred to new tubes. Total protein concentration estimated using bicinchoninic acid (BCA) protein assay (Thermo Scientific, IL, USA) and/or Direct Detect $^{\mathrm{tm}}$ Spectrometer (EMD Millipore Corporation, MA, USA), as per manufacturers' instructions.

\section{Western blotting}

Lysates mixed with $4 \times$ Laemmli sample buffer $(62.5 \mathrm{mM}$ Tris $-\mathrm{HCl} \mathrm{pH}$ 6.8, $10 \%$ v/v glycerol, $1 \%$ v/v SDS, $0.005 \%$ w/v bromophenol blue, $355 \mathrm{mM} 2$ mercaptoethanol) in PBS to give total protein/lane of 6-10 $\mu \mathrm{g}$ (tropomyosin) or 25-35 $\mu \mathrm{g}$ (HIF- $1 \alpha / 2 \alpha)$. Samples heated for 5 mins at $95{ }^{\circ} \mathrm{C}$ and loaded onto $12.5 \%$ (tropomyosin) or $8 \%(\mathrm{HIF}-1 / 2 \alpha)$ v/v SDSPAGE gels with Precision Plus Protein ${ }^{\mathrm{Tx}}$ standards (Bio-Rad, CA, USA). Gel electrophoresis performed in running buffer (1.0 L milli-Q $\mathrm{H}_{2} \mathrm{O}, 2.9 \mathrm{~g}$ Tris, $14.5 \mathrm{~g}$ glycine, $1 \mathrm{~g}$ SDS) at $120 \mathrm{~V}$ (Mini-PROTEAN ${ }^{\circ}$ Tetra Cell; Bio-Rad, CA, USA). Proteins transferred to Immobilon-P polyvinylidene difluoride (PVDF) membranes (Millipore, MA, USA) in transfer buffer (1.6 L milli-Q $\mathrm{H}_{2} \mathrm{O}, 400 \mathrm{~mL}$ methanol, $5.8 \mathrm{~g}$ Tris, $29 \mathrm{~g}$ glycine) for $2 \mathrm{~h}$ at $80 \mathrm{~V}$ on ice.

Membranes blocked in $5 \% \mathrm{w} / \mathrm{v}$ skim milk (SM) in Tris-buffered saline containing $0.1 \% \mathrm{v} / \mathrm{v}$ Tween-20 (TBST) for 30 mins at RT. Membranes then incubated with primary antibody diluted as per Table 1 in $2 \% \mathrm{w} / \mathrm{v}$ SM/TBST for $2 \mathrm{~h}$ at RT with constant agitation (tropomyosin and actin) or in $5 \% \mathrm{w} / \mathrm{v}$ SM/TBST overnight at $4{ }^{\circ} \mathrm{C}(\mathrm{HIF}-1 / 2 \alpha)$. Membranes washed thrice in TBST and incubated with appropriate HRP-conjugated secondary antibody (Table 1 ) in $2 \% \mathrm{v} / \mathrm{v} \mathrm{SM} / \mathrm{TBST}$ for $1 \mathrm{~h}$ at RT. Membranes washed thrice in TBST, incubated with enhanced chemiluminescence (ECL) reagents (GE Healthcare, Amersham, UK) and visualized using medical radiographic film (Fuji Medical, Tokyo, Japan) or
ImageQuant $^{\text {Th }}$ LAS-4000 (GE Healthcare, Munich, Germany). Densitometry performed on ImageJ. All results normalized to $\mathrm{C} 4$ actin loading control.

\section{Statistical analysis}

Statistical analysis was conducted using two-sided ttests, or two-way ANOVA when testing three or more means (GraphPad Prism V6.0). Results are mean \pm SEM. $P<0.05$ was considered statistically significant.

\section{Results}

Hypoxia increases the levels of HIF-1a and HIF-2a in SH-EP neuroblastoma cells

HIF- $1 \alpha$ and HIF- $2 \alpha$ are commonly used markers of cellular hypoxia and these were used to confirm induction of hypoxia. Expression levels of both HIF- $1 \alpha$ and HIF$2 \alpha$ increased as early as $8 \mathrm{~h}$ following hypoxic incubation compared with normoxic control cells (Additional file 1: Figure S1). HIF-1 $\alpha$ levels increased from 8 to $144 \mathrm{~h}$ hypoxia, while hypoxia-induced HIF- $2 \alpha$ expression peaked at $96 \mathrm{~h}$.

\section{Neuroblastoma proliferation is increased by hypoxia}

Aggressive cancer phenotypes are characterised by increased cellular proliferation. Given that a dynamic actin cytoskeleton is required for proliferation and the transcription factor HIF- $2 \alpha$ promotes growth, we investigated the impact of hypoxia on SH-EP cell proliferation. SH-EP were cultured in normoxic and hypoxic conditions for 24-144 $\mathrm{h}$ and cell number was determined using trypan blue exclusion. Hypoxic cell counts were significantly increased at 72 and $120 \mathrm{~h}$ when normalized to parallel normoxic cell cultures $(P=0.007$ and $P=0.01$, respectively; Fig. 1a). Following confirmation of physiological hypoxia at the abovementioned timepoints (8-144 h), we proceeded to examine other aspects of the hypoxic neuroblastoma phenotype.

\section{Neuroblastoma cell invasiveness is reduced by hypoxia}

Cellular invasiveness was measured by a QCM invadopodia assay, which examined degradation of a fluorescent gelatin matrix while controlling for cell number and size. DAPI images (Fig. 1b) were thresholded to provide cell counts (Fig. 1c), while thresholding TRITC-phalloidin images (Fig. 1d) provided cell area values (Fig. 1e). Thresholding GFP images (Fig. 1f) provided matrix degradation areas (Fig. 1g). Hypoxia significantly reduced gelatin degradation per cell area at $72 \mathrm{~h}$ (Fig. 1h), though no significant difference was observed at $96 \mathrm{~h}$ (Fig. 1i).

\section{Hypoxia promotes a more organized actin cytoskeleton}

A dynamic actin cytoskeleton is fundamental to cell migration and invasion. We therefore examined actin cytoskeletal organization to understand the reduction in 

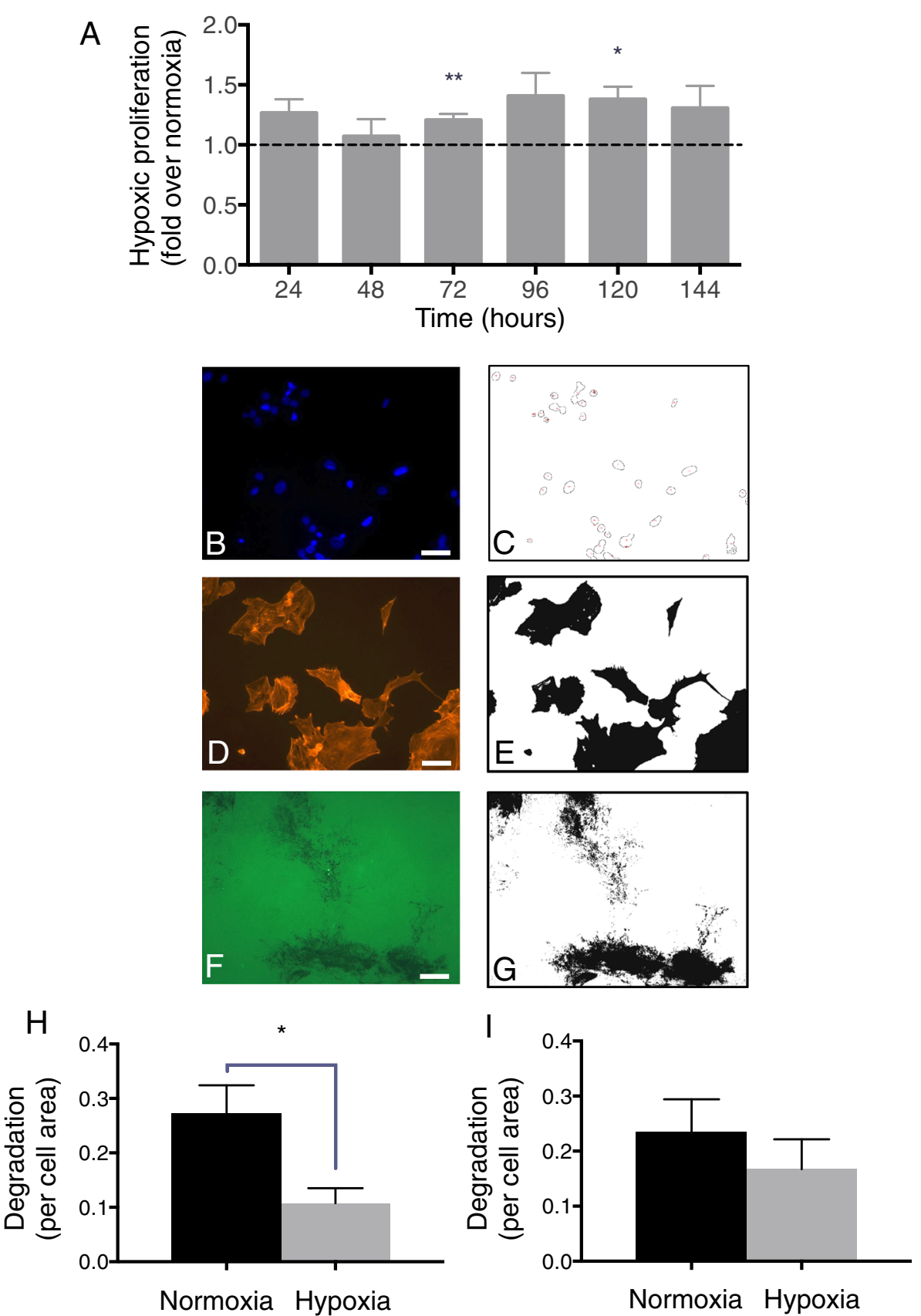

Fig. 1 Hypoxia alters the behavior of SH-EP neuroblastoma cells. a SH-EP cells were grown in normoxic $\left(20 \% \mathrm{O}_{2}\right)$ and hypoxic conditions (1 \% $\left.\mathrm{O}_{2}\right)$ for 24-144 h. Hypoxic cell viability normalized to normoxic controls (dashed line through 1). b-i Representative images of a chamber slide (8-well) coated with an extracellular matrix mimic, GFP-tagged gelatin, seeded with $1.6 \times 10^{4} \mathrm{SH}$-EP/well. After 72-96 h \pm hypoxia, cells fixed in methanol and stained with DAPI and TRITC-phalloidin. Five fields of view (20x objective) were obtained for each well using a widefield microscope and images imported into Image J for analysis. DAPI nuclear counts (b, c) provided cell numbers. Thresholding on phalloidin (d, e) and the absence of GFP (f, $\mathbf{g})$ provided cell and matrix degradation areas, respectively. Hypoxia resulted in decreased gelatin degradation per cell area at $72 \mathrm{~h}(\mathbf{h})$, although no significance was observed at $96 \mathrm{~h}$ (i). 1,000+ cells analysed per timepoint. Data is mean \pm SEM; $n=4(\mathbf{a}), n=3$ (b-i). * $P<0.05$, ** $P<0.01$ (t-test). Scale bar $=50 \mu \mathrm{m}$

matrix degradation observed at $72 \mathrm{~h}$ hypoxia. Normoxic cells stained with TRITC-phalloidin, which binds to filamentous actin, displayed a disordered actin cytoskeleton (Fig. 2a, b), while hypoxic cells displayed a strong increase in actin cytoskeletal organization (Fig. 2c, d). In particular, hypoxia consistently increased the number of parallel actin filament bundles per cell. The actin-binding protein $\alpha$-actinin cross-links parallel actin filaments [43], 


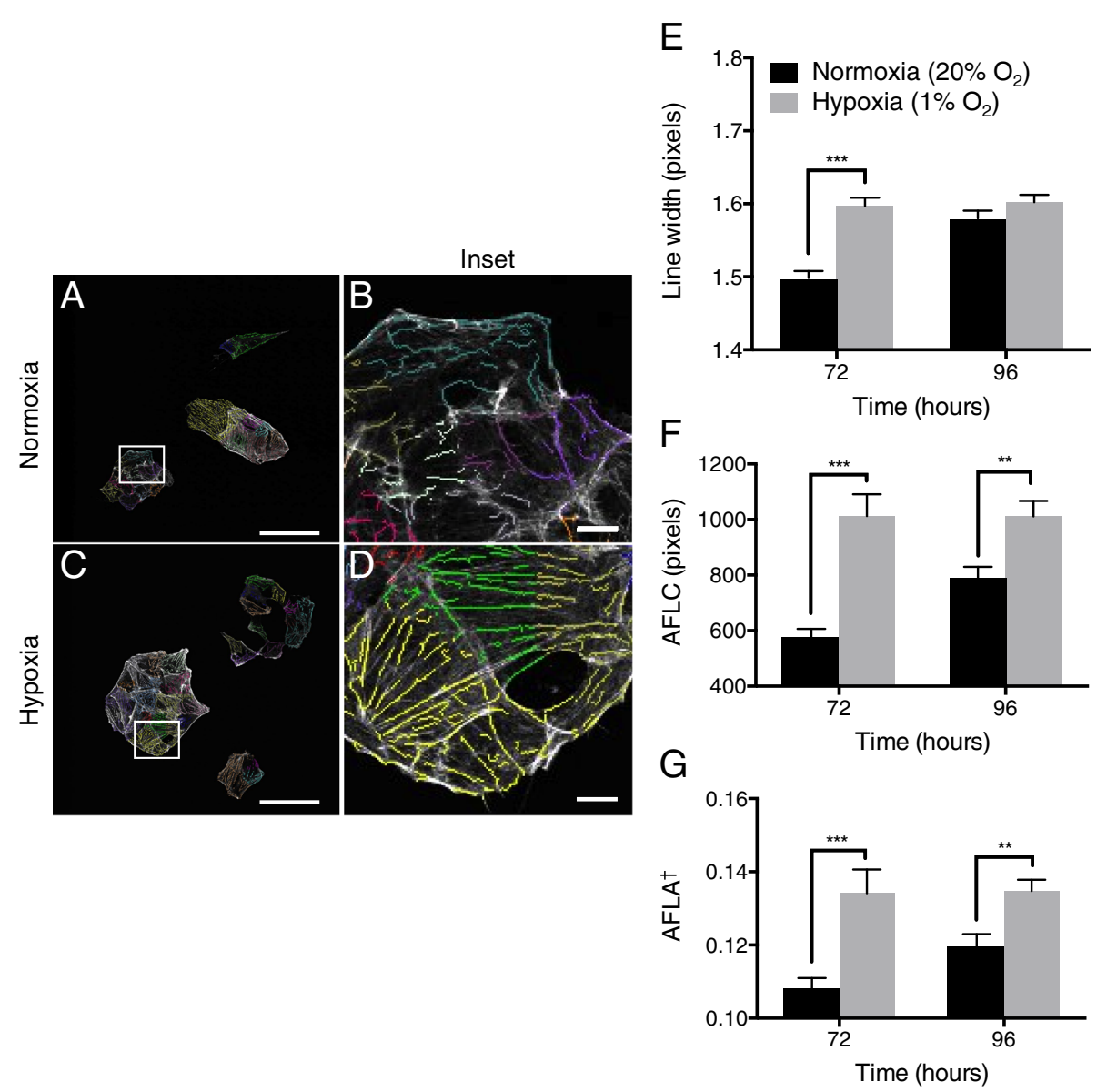

Fig. 2 Hypoxia leads to a more ordered actin cytoskeleton. SH-EP cells were grown in normoxia $\left(20 \% \mathrm{O}_{2}\right)$ or hypoxia $\left(1 \% \mathrm{O}_{2}\right)$ for 72 - 96 h. Coverslips were fixed with $4 \%$ PFA and stained with TRITC-phalloidin and DAPI. Single z-plane images were obtained by confocal microscopy. Linear feature detection software was used to quantitate actin cytoskeletal organization. a-d Representative linear detection after $72 \mathrm{~h} \pm$ hypoxia. Hypoxia visibly increases the number of actin filament bundles known as stress fibres (b vs. d). Scale bar $=50 \mu \mathrm{m}$, or $5 \mu \mathrm{m}$ in inset. e Hypoxia increases mean actin filament bundle width at $72 \mathrm{~h}$. $\mathbf{f}$ Hypoxia increases total actin filament length per cell number (AFLC) and (g) per cell area (AFLA). Data is mean \pm SEM $(n=3) .650+$ cells analysed per timepoint. ${ }^{* *} P<0.01,{ }^{* * *} P<0.0001$ (t-test). ${ }^{\dagger}$ AFLA is dimensionless, with [length (pixels)]/[area (pixels)]

enhances the invasive potential of cancer cells [44] and is associated with poor prognosis in a variety of tumors $[45,46]$. For these reasons we examined $\alpha$-actinin expression as a potential explanation for increased parallel bundles of actin filaments with hypoxia. However, no statistically significant change in expression was observed between normoxic and hypoxic incubations of up to $144 \mathrm{~h}$ (data not shown).

Using a linear-feature detection algorithm [42] we quantitated various cytoskeletal parameters, including actin filament bundle width and length (Fig. 2e-g). Mean actin filament bundle width was significantly increased by $72 \mathrm{~h}$ hypoxic incubation (Fig. 2e). Actin filament length per cell (AFLC; Fig. 2f) and per cell area (AFLA; Fig. 2g) were significantly increased by 72-96 h hypoxia. The effect of hypoxia on AFLC and AFLA was significant $(P<0.0001,2$ way ANOVA).
Expression of HMW tropomyosin isoforms, $\mathrm{Tm} 1$ and $\mathrm{Tm} 2$, are altered by hypoxia

Due to the 'master regulatory' role of tropomyosins in the actin cytoskeleton [34], changes in tropomyosin expression and localization could provide mechanistic insight into our observed hypoxia-induced reorganization of actin filaments. Clear changes were observed in HMW tropomyosin levels in hypoxic SH-EP cells compared with normoxic controls. HMW isoforms Tm1, Tm2 and Tm3 were detected by immunoblotting with the $\alpha / 9 \mathrm{~d}$ antibody (Fig. 3a). Tm1 expression increased significantly over normoxic controls with 72-96 h hypoxia (Fig. 3b), while Tm2 levels increased significantly above normoxia after $96 \mathrm{~h}$ hypoxia (Fig. 3c). Although hypoxic Tm3 expression trended upward with time, no statistically significant changes were observed (Fig. 3d). 
A

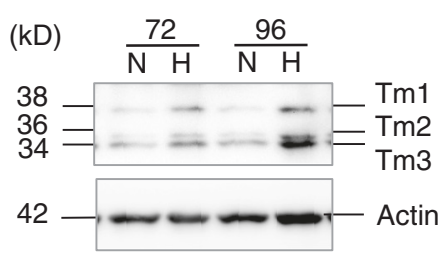

C

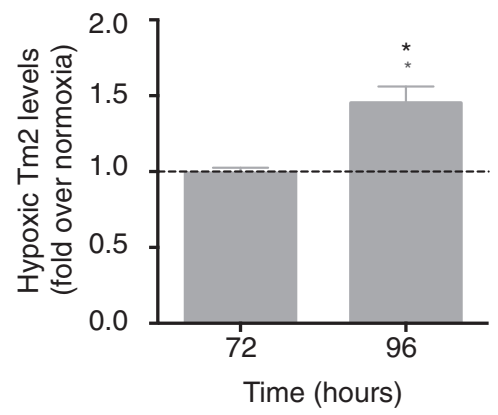

Tm1/2/3

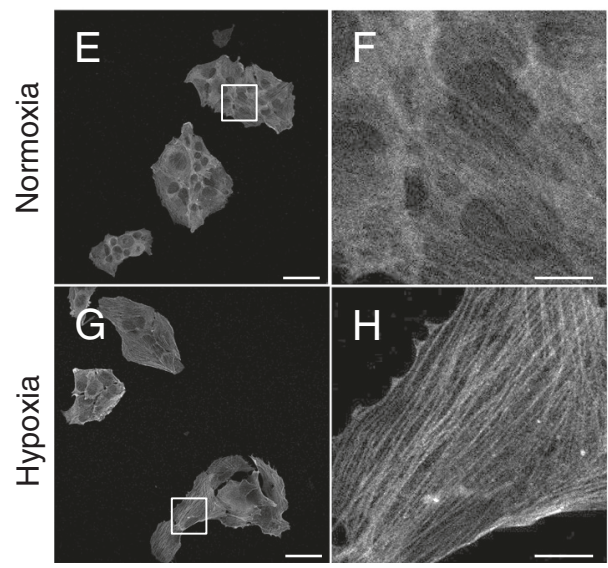

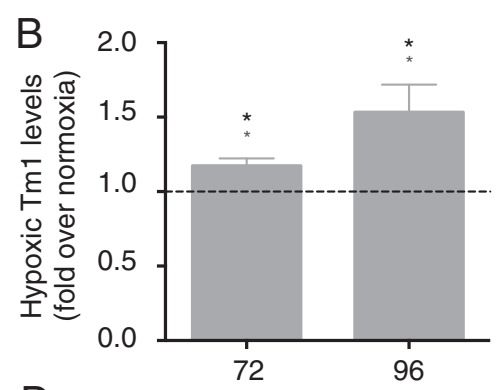

D

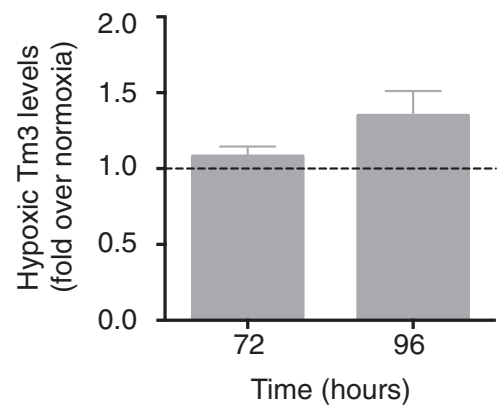

Tm2/3

Inset

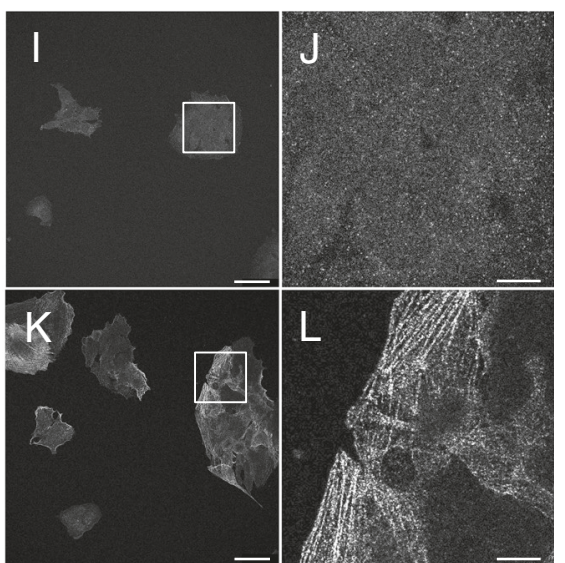

Fig. 3 Hypoxia alters the expression and localization of HMW tropomyosins. a Normoxic $(N)$ and hypoxic $(H)$ SH-EP lysates were separated by SDS-PAGE. Representative Western blot stained with a9d antibody, which detects HMW tropomyosin isoforms Tm1, Tm2 and Tm3. Actin used loading control. Densitometry values were normalized to normoxic levels (dashed line) for Tm1 (b), Tm2 (c) and Tm3 (d) expression. Results are mean \pm SEM; $n=3-4, * P<0.05, * * P<0.01$ (t-test). e-I SH-EP cells were grown for $72 \mathrm{~h} \pm$ hypoxia, fixed, permeabilized and incubated with Tm311 and CGB6 antibodies to detect HMW isoforms Tm1/2/3 (e-h) and Tm2/3 (e-h), respectively. Cells then incubated with Alexa555-tagged goat anti-mouse and single z-plane images obtained by confocal microscopy. Hypoxia increased filamentous organization of Tm1/2/3 (f vs. h) and Tm2/3 (j vs. I) compared to normoxic control cells. Independent experiments (Tm311, $n=2 ;$ CG $\beta 6, n=5$ ). Scale bar $=50 \mu m, 10 \mu m$ in inset

Hypoxia increases HMW tropomyosin-containing filaments Tropomyosins may modulate the actin cytoskeleton in an isoform-specific manner through changes in their intracellular distribution [34]. Cells incubated with antibodies that detect HMW tropomyosin isoforms (Tm1/2/3) displayed an increase in filamentous structures at $72 \mathrm{~h}$ hypoxia (Fig. 3g, h) compared with normoxia (Fig. 3e, f). To better discern the role of individual isoforms, we stained for $\operatorname{Tm} 2 / 3$ (CGß6 antibody).
More Tm2/3-containing filaments were observed in hypoxia (Fig. 3k, l) compared to normoxia (Fig. 3i, j).

\section{Expression and intracellular organization of LMW tropomyosin isoforms are unaltered by hypoxia}

Hypoxia did not induce statistically significant changes in expression of the LMW isoforms Tm4 (Fig. 4a, d), Tm5NM1/2 (Fig. 4b, e), nor Tm5NM1-11 (Fig. 4c, f). Similarly, no hypoxia-induced changes in intracellular 


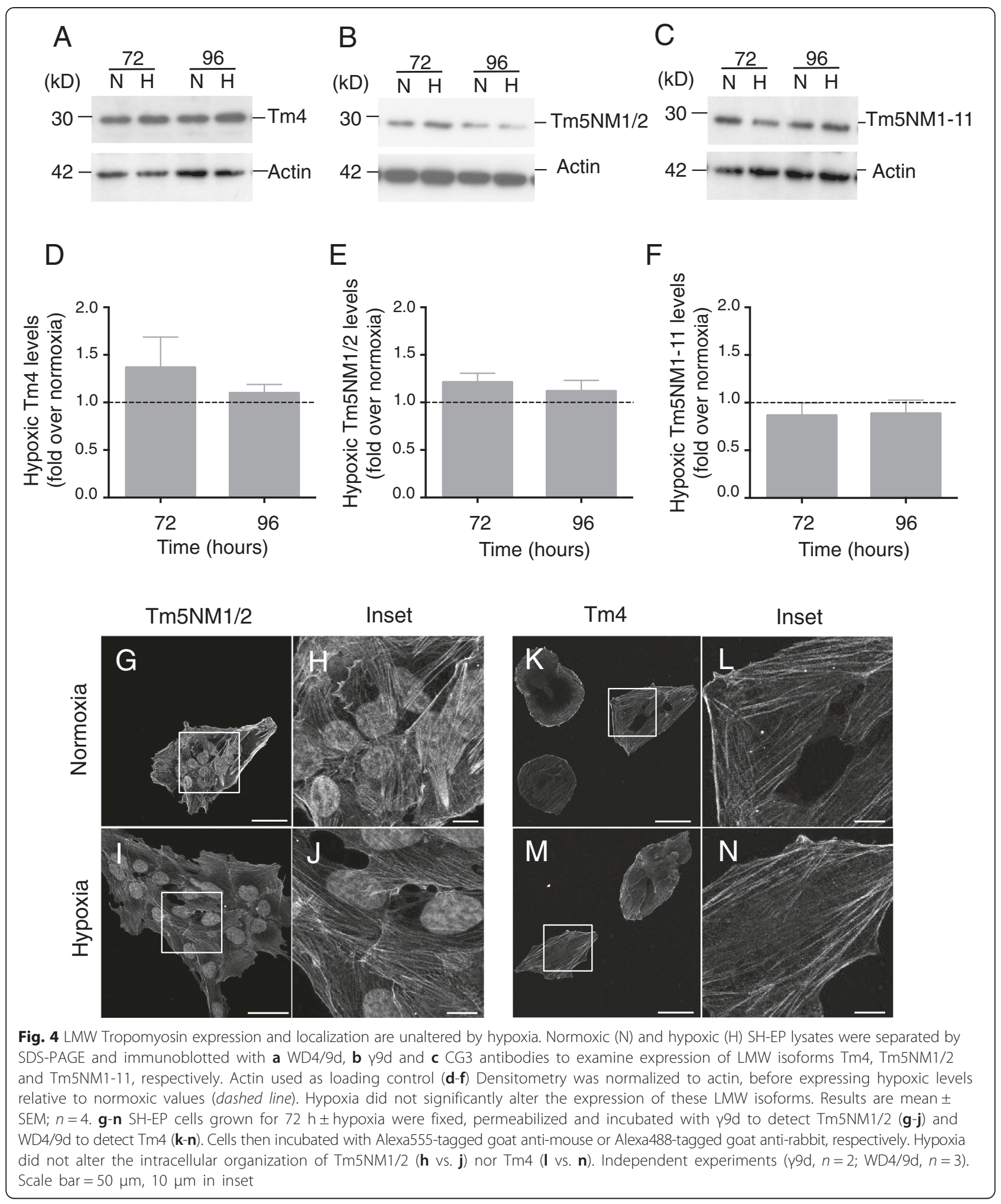


organization were observed for Tm5NM1/2 (Fig. 4g-j) and Tm4 (Fig. 4k-n).

\section{Discussion}

Given the essential roles of the actin cytoskeleton in aggressive hypoxic phenotypes, it is surprising that the actin cytoskeleton as a mediator of the hypoxic response has remained largely unexplored until recently [33].

Few studies have examined the effect of hypoxia on neuroblastoma proliferation. However, our observed increase in hypoxic SH-EP proliferation is consistent with a documented marginal increase in SH-EP cell number after $48 \mathrm{~h}$ hypoxia [47]. We offer two theories to explain our observation. First, HIF-2 $\alpha$ enhances the activity of the oncogenic transcription factor, c-Myc [48], which increases cell proliferation by driving the $G_{1} / S$ cell cycle transition [49]. Therefore, hypoxic induction of HIF- $2 \alpha$ should promote cell proliferation. Second, hypoxic $\mathrm{BE}(2) \mathrm{C}$ cells $(72 \mathrm{~h})$ induced the expression of both growth factors and growth factor receptors, including VEGF, IGF2, NRP1 and NGFR [16]. Hypoxia might therefore induce autocrine growth and survival loops that drive proliferation.

It is known that $72 \mathrm{~h}$ hypoxia induces a 'fibroblastoid' phenotype in neoplastic cells of epithelial origin [50]. This suggests involvement of the actin cytoskeleton-a key determinant of cellular morphology-in the hypoxic phenotype. A dynamic actin cytoskeleton is necessary for enhanced migration and invasion [28] and it is likely that our observed hypoxia-induced strengthening of actin cytoskeletal organization-increased actin filament bundle width and length-led to reduced actin dynamics.

Our observation that hypoxia reduced SH-EP cell invasiveness is in contrast to a recent study where hypoxia significantly increased $\mathrm{BE}(2) \mathrm{C}$ invasion through Matrigel-coated membranes [51]. However, hypoxia was mimicked using deferoxamine mesylate and the invasive phenotype was examined after 24 h hypoxia. Hypoxia also increased neuroblastoma Kelly cell invasion through Matrigel-coated membranes after treating cells to 24-48 h hypoxia [13]. However, these cells were re-oxygenated during the invasion assay. In contrast to SH-EP, which reportedly contain no MYCN mRNA [52], all cell lines displaying increased hypoxic invasiveness were MYCNamplified. This suggests hypoxia-induced invasion is cellline-specific and might implicate MYCN status.

The tropomyosin family of actin-associating proteins are known to interact with and regulate actomyosin structures, including actin filament stress fibres. Hypoxia induced the expression of $35 \mathrm{kD}$ and $36.5 \mathrm{kD}$ HMW tropomyosins in porcine pulmonary arterial epithelial cells (PAEC) [53] and it is possible that up-regulated 34 $\mathrm{kD}$ and $36 \mathrm{kD}$ proteins in hypoxic human and bovine
PAEC were also HMW tropomyosins [54, 55]. However, mammalian evidence of hypoxia-induced tropomyosin synthesis has until now been restricted solely to endothelial cells.

Hypoxia starves cells of energy and a concomitant reduction in protein synthesis is required to maintain essential housekeeping functions. This reversible reduction in overall protein synthesis is HIF-independent [56, 57]. Increased Tm1 and Tm2 levels after 3-4 days hypoxia suggests these proteins must serve a critical, protective role against hypoxic stress, analogous to the induction of heat-shock proteins in hyperthermia [58]. The HMW isoforms $\operatorname{Tm} 1$ and $\operatorname{Tm} 2$ increase the stability of actin stress fibres [59] and partially protect actin filaments from the severing actions of gelsolin [60, 61]. Moreover, $\mathrm{Tm} 1$ and $\mathrm{Tm} 2$ display tumor suppressor activity in a range of transformed and tumor cell lines [62-67]. As a dynamic actin cytoskeleton is required for migration and invasion, increased $\mathrm{Tm} 1$ and $\mathrm{Tm} 2$ expression, and their recruitment to actin filaments, can largely explain the reduced SH-EP invasion at $72 \mathrm{~h}$ hypoxia. Presumably, this prevents the energy expenditure associated with actin dynamics. Reduced actin dynamics and induction of tumor suppressor proteins is in stark contrast to the entire notion of an aggressive hypoxia phenotype. It is therefore interesting that expression of these tumorsuppressor isoforms decreased below normoxic levels at $144 \mathrm{~h}$ hypoxia (data not shown). We postulate that chronically hypoxic SH-EP might become permissive of the archetypal aggressive phenotype.

The structural and spatial organization of the actin cytoskeleton is highly sensitive to reactive oxygen species (ROS), such as hydrogen peroxide $\left(\mathrm{H}_{2} \mathrm{O}_{2}\right)$ [68]. In particular, ROS exposure results in a net increase of free barbed ends and a dramatic increase in actin polymerization [69]. More recently, oxidation of nonmuscle actin was shown to result in depolymerization of actin filaments and a complete loss of polymerizability [70]. As hypoxia is known to increase intracellular ROS, primarily by the mitochondria [71-73], increased expression of $\mathrm{Tm} 1$ and $\mathrm{Tm} 2$ may represent an attempt to protect the actin cytoskeleton from oxidative stress. In addition, exposure of human endothelial cells to the ROS, $\mathrm{H}_{2} \mathrm{O}_{2}$, induced ERK-mediated phosphorylation of Tm1, followed by the rapid colocalization with actin and stress fibres [74]. Therefore, the protection afforded by HMW tropomyosins may be a result of increased expression and posttranslational modification that increases their association with the hypoxic actin cytoskeleton.

Altered expression of tropomyosins in hypoxic neuroblastoma cells may involve epigenetic alterations to HMW promoter regions. The TPM1 gene (encoding Tm2) is silenced in metastatic breast and colon cancer 
cell lines by promoter hyper-methylation. Treatment of these cells with the de-methylating agent 5-aza-2'-deoxycytidine (5-aza-dC) reactivated TPM1 gene expression [75]. Another study demonstrated 5-aza-dC treatment induced up-regulation of TPM2 (encoding Tm1), but not TPM1, in metastatic breast cancer cells [76], while TPM1 and TPM2 were both up-regulated in demethylated fibrosarcoma cells [77]. As hypoxia induces global hypomethylation [78], we postulate that hypoxia leads to the 'de-repression' of tropomyosin expression. Interestingly, most pathways that repress tropomyosin expression affect HMW, but not LMW, tropomyosin isoforms (reviewed in Gunning et al. [34]). HMW isoforms contain the 1a exon, while $\mathrm{LMW}$ isoforms contain the $1 \mathrm{~b}$ exon. As cancer leads to hyper-methylation of $\mathrm{CpG}$ islands [78], we performed a qualitative examination of the $\mathrm{CpG}$ islands flanking the 1a and $1 \mathrm{~b}$ exons. This revealed a substantially higher CG content flanking the HMW 1a exon over the LMW 1b exon. This suggests exon 1a-containing HMW tropomyosins may be more susceptible to a hypoxic de-repression of gene expression.

\section{Conclusions}

Hypoxic induction of the tumor-suppressor isoforms, Tm1 and $\operatorname{Tm} 2$, might represent an early stress response. Beyond stabilizing the actin filaments, these tropomyosins might protect the actin cytoskeleton from hypoxic stresses that include increased ROS. Changes in actin organization characteristic of reversion of the transformed phenotype are induced by hypoxia at 72-96 h in SH-EP neuroblastoma cells. This is mirrored by increased organization of HMW tropomyosin-containing filaments. However, maximum expression of HMW tropomyosins (96 h) did not correlate with the most significant changes in the cytoskeleton (72 h). Hence, there is no evidence that changes in tropomyosin expression alone can drive the observed cytoskeletal alterations and the increased expression of HMW tropomyosins may be in response to their recruitment into stress fibres. This dissociation of tropomyosin isoform expression and actin organization is intriguing and suggests that other mechanisms may be at work. These findings warrant further investigation into the potential role of tropomyosins in driving hypoxic actin reorganization.

\section{Additional file}

Additional file 1: Figure S1. Hypoxic incubation of SH-EP neuroblastoma cells increases levels of hypoxia-inducible transcription factors, HIF-1a and HIF-2a. SH-EP cells were incubated for $0-144 \mathrm{~h}$ in normoxic $\left(20 \% \mathrm{O}_{2}\right)$ or hypoxic $\left(1 \% \mathrm{O}_{2}\right)$ conditions, before rapidly lysing cells on ice in RIPA buffer containing a protease inhibitor cocktail. Protein lysates were separated using SDS-PAGE and HIFs detected using anti-HIF-1a or anti-HIF-2a antibodies. Representative immunoblots, with HIF expression clearly upregulated in hypoxia $(H)$ over normoxic controls $(M)$. Cell lysates known to contain HIF-1a and HIF-2a used as positive control (+ve). $n=3$. (PDF $1900 \mathrm{~kb}$ )

\section{Abbreviations}

HIF: Hypoxia-inducible factor; HMW: High molecular weight; LMW: Low molecular weight.

\section{Competing interests}

PWG is a member of the Board of, and JRS is currently employed by, Novogen, a company which is commercializing the use of anti-tropomyosin drugs to treat cancer. JJG and PAP declare that they have no competing interests.

\section{Authors' contributions}

JJG was involved in the study design, data collection, data interpretation and drafted the manuscript. JRS and PAP were involved in the study design, acquisition of data and interpretation of data. PWG was involved in the study design, interpretation of data and supervision of the research group. All authors read, revised and approved the final manuscript.

\section{Acknowledgements}

The authors would like to thank Alyce Nehme and Melissa Desouza for technical assistance and feedback with early stages of manuscript preparation, and Leanne Bischof, Computational Informatics Department, CSIRO, for the development of and assistance with the linear feature algorithm

\section{Author details}

${ }^{1}$ Oncology Research Unit, School of Medical Sciences, UNSW Australia, Room 229, Wallace Wurth Building, Sydney, NSW 2052, Australia. Pancreatic Cancer Translational Research Group, Lowy Cancer Research Centre, UNSW Australia, Sydney, NSW 2052, Australia. ${ }^{3}$ Current address: ARC Centre of Excellence in Convergent Bio-Nano Science and Technology, and Department of Microbiology and Immunology, The University of Melbourne, at the Peter Doherty Institute for Infection and Immunity, Melbourne, VIC 3010, Australia.

Received: 30 July 2015 Accepted: 9 October 2015

Published online: 16 October 2015

\section{References}

1. Park JR, Eggert A, Caron H. Neuroblastoma: biology, prognosis, and treatment. Pediatr Clin North Am. 2008;55(1):97-120.

2. Mueller S, Matthay KK. Neuroblastoma: biology and staging. Curr Oncol Rep. 2009:11(6):431-8.

3. Howman-Giles R, Shaw PJ, Uren RF, Chung DK. Neuroblastoma and other neuroendocrine tumors. Semin Nucl Med. 2007;37(4):286-302.

4. DuBois SG, Kalika Y, Lukens JN, Brodeur GM, Seeger RC, Atkinson JB, et al. Metastatic sites in stage IV and IVS neuroblastoma correlate with age, tumor biology, and survival. J Pediatr Hematol Oncol. 1999;21(3):181-9.

5. Haupt R, Garaventa A, Gambini C, Parodi S, Cangemi G, Casale F, et al. Improved survival of children with neuroblastoma between 1979 and 2005: a report of the Italian Neuroblastoma Registry. J Clin Oncol. 2010;28(14):2331-8.

6. Hanahan D, Weinberg RA. Hallmarks of cancer: the next generation. Cell. 2011;144(5):646-74.

7. Konerding M, Fait E, Gaumann A. 3D microvascular architecture of precancerous lesions and invasive carcinomas of the colon. $\mathrm{Br} J$ Cancer. 2001;84(10):1354.

8. Reynolds TY, Rockwell S, Glazer PM. Genetic instability induced by the tumor microenvironment. Cancer Res. 1996;56(24):5754-7.

9. Brown JM, Wilson WR. Exploiting tumour hypoxia in cancer treatment. Nat Rev Cancer. 2004;4(6):437-47.

10. Tredan O, Galmarini CM, Patel K, Tannock IF. Drug resistance and the solid tumor microenvironment. J Natl Cancer Inst. 2007;99(19):1441-54. doi:10.1093/jnci/djm135.

11. Hussein D, Estlin EJ, Dive C, Makin GW. Chronic hypoxia promotes hypoxia-inducible factor-1a-dependent resistance to etoposide and vincristine in neuroblastoma cells. Mol Cancer Ther. 2006;5(9):2241-50.

12. Sullivan R, Paré GC, Frederiksen $\sqcup$, Semenza GL, Graham CH. Hypoxia-induced resistance to anticancer drugs is associated with decreased senescence and requires hypoxia-inducible factor-1 activity. Mol Cancer Ther. 2008;7(7):1961-73.

13. Ginis I, Faller DV. Hypoxia affects tumor cell invasiveness in vitro: the role of hypoxia-activated ligand HAL1/13 (Ku86 autoantigen). Cancer Lett. 2000;154(2):163-74. 
14. Jögi A, Øra I, Nilsson H, Lindeheim Å, Makino Y, Poellinger L, et al. Hypoxia alters gene expression in human neuroblastoma cells toward an immature and neural crest-like phenotype. Proc Natl Acad Sci U S A. 2002;99(10):7021-6.

15. Axelson $H$, Fredlund $E$, Ovenberger $M$, Landberg $G$, Påhlman S. Hypoxia-induced dedifferentiation of tumor cells-a mechanism behind heterogeneity and aggressiveness of solid tumors. Semin Cell Dev Biol. 2005;16(4):554-63. doi:10.1016/j.semcdb.2005.03.007.

16. Jögi A, Vallon-Christersson J, Holmquist L, Axelson H, Borg Å, Påhlman S. Human neuroblastoma cells exposed to hypoxia: induction of genes associated with growth, survival, and aggressive behavior. Exp Cell Res. 2004;295(2):469-87.

17. Poomthavorn P, Wong SH, Higgins S, Werther GA, Russo VC. Activation of a prometastatic gene expression program in hypoxic neuroblastoma cells. Endocr Relat Cancer. 2009;16(3):991-1004.

18. Keith B, Johnson RS, Simon MC. HIF1a and HIF2a: sibling rivalry in hypoxic tumour growth and progression. Nat Rev Cancer. 2011;12(1):9-22.

19. Semenza G. Hypoxia-inducible factors in physiology and medicine. Cell. 2012;148(3):399-408. doi:10.1016/j.cell.2012.01.021.

20. Wang GL, Jiang BH, Rue EA, Semenza GL. Hypoxia-inducible factor 1 is a basic-helix-loop-helix-PAS heterodimer regulated by cellular $\mathrm{O} 2$ tension. Proc Natl Acad Sci U S A. 1995;92(12):5510-4.

21. Bruick RK, McKnight SL. A conserved family of prolyl-4-hydroxylases that modify HIF. Sci Signal. 2001;294(5545):1337-40.

22. Ivan M, Kondo K, Yang H, Kim W, Valiando J, Ohh M, et al. HIFalpha targeted for VHL-mediated destruction by proline hydroxylation: implications for $\mathrm{O} 2$ sensing. Sci Signal. 2001;292(5516):464-8.

23. Maxwell PH, Wiesener MS, Chang G-W, Clifford SC, Vaux EC, Cockman ME, et al. The tumour suppressor protein VHL targets hypoxia-inducible factors for oxygen-dependent proteolysis. Nature. 1999:399(6733):271-5.

24. Holmquist-Mengelbier L, Fredlund E, Löfstedt T, Noguera R, Navarro S, Nilsson $\mathrm{H}$, et al. Recruitment of HIF-1a and HIF-2a to common target genes is differentially regulated in neuroblastoma: HIF-2a promotes an aggressive phenotype. Cancer Cell. 2006;10(5):413-23.

25. Noguera R, Fredlund E, Piqueras M, Pietras A, Beckman S, Navarro S, et al. HIF-1a and HIF-2a are differentially regulated in vivo in neuroblastoma: high HIF-1a correlates negatively to advanced clinical stage and tumor vascularization. Clin Cancer Res. 2009;15(23):7130-6.

26. Chen $S$, Zhang $M$, Xing $L$, Wang $Y$, Xiao $Y$, Wu Y. HIF-1 a contributes to proliferation and invasiveness of neuroblastoma cells via $\mathrm{SHH}$ signaling. Plos One. 2015:10(3):e0121115.

27. Stevenson RP, Veltman D, Machesky LM. Actin-bundling proteins in cancer progression at a glance. J Cell Sci. 2012;125(5):1073-9.

28. Yamaguchi $\mathrm{H}$, Condeelis J. Regulation of the actin cytoskeleton in cancer cell migration and invasion. Biochim Biophys Acta. 2007;1773(5):642-52. doi:10.1016/j.bbamcr.2006.07.001.

29. Böhmer R, Scharf E, Assoian RK. Cytoskeletal integrity is required throughout the mitogen stimulation phase of the cell cycle and mediates the anchorage-dependent expression of cyclin D1. Mol Biol Cell. 1996;7(1):101-11.

30. Desouza M, Gunning PW, Stehn JR. The actin cytoskeleton as a sensor and mediator of apoptosis. Bioarchitecture. 2012;2(3):75-87.

31. Gourlay CW, Ayscough KR. The actin cytoskeleton: a key regulator of apoptosis and ageing? Nat Rev Mol Cell Biol. 2005;6(7):583-9.

32. Ingber DE, Prusty D, Sun Z, Betensky H, Wang N. Cell shape, cytoskeletal mechanics, and cell cycle control in angiogenesis. J Biomech. 1995;28(12):1471-84

33. Vogler M, Vogel S, Krull S, Farhat K, Leisering P, Lutz S, et al. Hypoxia modulates fibroblastic architecture, adhesion and migration: a role for HIF1a in cofilin regulation and cytoplasmic actin distribution. PLoS One. 2013;8(7):1. doi:10.1371/journal.pone.0069128.

34. Gunning P, O'Neill G, Hardeman E. Tropomyosin-based regulation of the actin cytoskeleton in time and space. Physiol Rev. 2008;88(1):1-35.

35. Greenfield NJ, Huang YJ, Swapna G, Bhattacharya A, Rapp B, Singh A, et al. Solution NMR structure of the junction between tropomyosin molecules: implications for actin binding and regulation. J Mol Biol. 2006:364(1):80-96.

36. Gunning PW, Schevzov G, Kee AJ, Hardeman EC. Tropomyosin isoforms: divining rods for actin cytoskeleton function. Trends Cell Biol. 2005;15(6):333-41.

37. Helfman DM, Flynn P, Khan P, Saeed A. Tropomyosin as a regulator of cancer cell transformation. Tropomyosin. 2008;644:124-31.
38. Stehn JR, Haass NK, Bonello T, Desouza M, Kottyan G, Treutlein H, et al. A novel class of anticancer compounds targets the actin cytoskeleton in tumor cells. Cancer Res. 2013;73(16):5169-82.

39. Biedler JL, Helson L, Spengler BA. Morphology and growth, tumorigenicity, and cytogenetics of human neuroblastoma cells in continuous culture. Cancer Res. 1973;33(11):2643-52.

40. Biedler JL, Roffler-Tarlov S, Schachner M, Freedman LS. Multiple neurotransmitter synthesis by human neuroblastoma cell lines and clones. Cancer Res. 1978;38(11 Part 1):3751-7.

41. Robiolio M, Rumsey WL, Wilson DF. Oxygen diffusion and mitochondrial respiration in neuroblastoma cells. Am J Physiol Cell Physiol. 1989;256(6):C1207-C13.

42. Vindin H, Bischof L, Gunning P, Stehn J. Validation of an algorithm to quantify changes in actin cytoskeletal organization. J Biomol Screen. 2014;19(3):354-68.

43. Golji J, Collins R, Mofrad MR. Molecular mechanics of the a-actinin rod domain: bending, torsional, and extensional behavior. PLoS Comput Biol. 2009;5(5), e1000389.

44. Koizumi T, Nakatsuji H, Fukawa T, Avirmed S, Fukumori T, Takahashi M, et al. The role of Actinin-4 in bladder cancer invasion. Urology. 2010;75(2):357-64. doi:10.1016/j.urology.2009.09.037.

45. Fukushima S, Yoshida A, Honda K, Maeshima A, Narita Y, Yamada T, et al. Immunohistochemical actinin-4 expression in infiltrating gliomas: association with WHO grade and differentiation. Brain Tumor Pathol. 2014;31(1):11-6. doi:10.1007/s10014-013-0139-z.

46. Yamamoto S, Tsuda H, Honda K, Takano M, Tamai S, Imoto I, et al. ACTN4 gene amplification and actinin-4 protein overexpression drive tumour development and histological progression in a high-grade subset of ovarian clear-cell adenocarcinomas. Histopathology. 2012;60(7):1073-83.

47. Rössler J, Schwab M, Havers W, Schweigerer L. Hypoxia promotes apoptosis of human neuroblastoma cell lines with enhanced $\mathrm{N}$-myc expression. Biochem Biophys Res Commun. 2001;281(2):272-6. doi:10.1006/bbrc.2001.4342.

48. Gordan JD, Bertovrt JA, Hu C-J, Diehl JA, Simon MC. HIF-2a promotes hypoxic cell proliferation by enhancing c-myc transcriptional activity. Cancer Cell. 2007;11(4):335-47.

49. Pelengaris S, Khan M, Evan G. c-MYC: more than just a matter of life and death. Nat Rev Cancer. 2002;2(10):764-76.

50. Cannito S, Novo E, Compagnone A, di Bonzo LV, Busletta C, Zamara E, et al. Redox mechanisms switch on hypoxia-dependent epithelial-mesenchymal transition in cancer cells. Carcinogenesis. 2008;29(12):2267-78.

51. Park S, Kim J, Kim Y. Mulberry leaf extract inhibits cancer cell stemness in neuroblastoma. Nutr Cancer. 2012;64(6):889-98.

52. Sadee W, Yu V, Richards M, Preis P, Schwab M, Brodsky F, et al. Expression of neurotransmitter receptors and myc protooncogenes in subclones of a human neuroblastoma cell line. Cancer Res. 1987:47(19):5207-12.

53. Rao U, Denslow ND, Block ER. Hypoxia induces the synthesis of tropomyosin in cultured porcine pulmonary artery endothelial cells. Am J Physiol Lung Cell Mol Physiol. 1994;267(3):L271-L81.

54. Zimmerman LH, Levine RA, Farber HW. Hypoxia induces a specific set of stress proteins in cultured endothelial cells. J Clin Invest. 1991;87(3):908-14.

55. Graven KK, Zimmerman LH, Dickson EW, Weinhouse GL, Farber HW. Endothelial cell hypoxia associated proteins are cell and stress specific. J Cell Physiol. 1993;157(3):544-54.

56. Liu L, Cash TP, Jones RG, Keith B, Thompson CB, Simon MC. Hypoxiainduced energy stress regulates mRNA translation and cell growth. Mol Cell. 2006;21(4):521-31. doi:10.1016/j.molcel.2006.01.010.

57. Arsham AM, Howell JJ, Simon MC. A novel hypoxia-inducible factorindependent hypoxic response regulating mammalian target of rapamycin and its targets. J Biol Chem. 2003;278(32):29655-60.

58. Åkerfelt M, Morimoto RI, Sistonen L. Heat shock factors: integrators of cell stress, development and lifespan. Nat Rev Mol Cell Biol. 2010;11(8):545-55.

59. Tojkander S, Gateva G, Schevzov G, Hotulainen P, Naumanen P, Martin C et al. A molecular pathway for myosin II recruitment to stress fibers. Curr Biol. 2011;21(7):539-50

60. Ishikawa R, Yamashiro S, Matsumura F. Annealing of gelsolin-severed actin fragments by tropomyosin in the presence of $\mathrm{Ca} 2+$. Potentiation of the annealing process by caldesmon. J Biol Chem. 1989;264(28):16764-70.

61. Ishikawa R, Yamashiro S, Matsumura F. Differential modulation of actin-severing activity of gelsolin by multiple isoforms of cultured rat cell tropomyosin. Potentiation of protective ability of tropomyosins by $83-\mathrm{kDa}$ nonmuscle caldesmon. J Biol Chem. 1989;264(13):7490-7. 
62. Boyd J, Risinger Jl, Wiseman RW, Merrick BA, Selkirk JK, Barrett JC. Regulation of microfilament organization and anchorage-independent growth by tropomyosin 1. Proc Natl Acad Sci U S A. 1995;92(25):11534-8.

63. Prasad G, Fuldner RA, Cooper HL. Expression of transduced tropomyosin 1 cDNA suppresses neoplastic growth of cells transformed by the ras oncogene. Proc Natl Acad Sci U S A. 1993;90(15):7039-43.

64. Raval GN, Bharadwaj S, Levine EA, Willingham MC, Geary RL, Kute T, et al. Loss of expression of tropomyosin-1, a novel class II tumor suppressor that induces anoikis, in primary breast tumors. Oncogene. 2003;22(40):6194-203.

65. Prasad G, Masuelli L, Raj M, Harindranath N. Suppression of src-induced transformed phenotype by expression of tropomyosin-1. Oncogene. 1999;18(11):2027-31.

66. Janssen R, Mier JW. Tropomyosin-2 cDNA lacking the 3'untranslated region riboregulator induces growth inhibition of v-Ki-ras-transformed fibroblasts. Mol Biol Cell. 1997;8(5):897-908.

67. Gimona M, Kazzaz JA, Helfman DM. Forced expression of tropomyosin 2 or 3 in v-Ki-ras-transformed fibroblasts results in distinct phenotypic effects. Proc Natl Acad Sci U S A. 1996;93(18):9618-23.

68. Dalle-Donne I, Rossi R, Milzani A, Di Simplicio P, Colombo R. The actin cytoskeleton response to oxidants: from small heat shock protein phosphorylation to changes in the redox state of actin itself. Free Radic Biol Med. 2001;31(12):1624-32. doi:10.1016/S0891-5849(01)00749-3.

69. Moldovan L, Moldovan NI, Sohn RH, Parikh SA, Goldschmidt-Clermont PJ. Redox changes of cultured endothelial cells and actin dynamics. Circ Res. 2000;86(5):549-57.

70. Lassing I, Schmitzberger F, Björnstedt M, Holmgren A, Nordlund P, Schutt $C E$, et al. Molecular and structural basis for redox regulation of $\beta$-actin. J Mol Biol. 2007;370(2):331-48.

71. Liu L, Wise DR, Diehl JA, Simon MC. Hypoxic reactive oxygen species regulate the integrated stress response and cell survival. J Biol Chem. 2008;283(45):31153-62.

72. Mansfield KD, Guzy RD, Pan Y, Young RM, Cash TP, Schumacker PT, et al. Mitochondrial dysfunction resulting from loss of cytochrome $\mathrm{c}$ impairs cellular oxygen sensing and hypoxic HIF-a activation. Cell Metab. 2005;1(6):393-9.

73. Lluis JM, Buricchi F, Chiarugi P, Morales A, Fernandez-Checa JC. Dual role of mitochondrial reactive oxygen species in hypoxia signaling: activation of nuclear factor-kB via c-SRC-and oxidant-dependent cell death. Cancer Res. 2007;67(15):7368-77.

74. Houle F, Rousseau S, Morrice N, Luc M, Mongrain S, Turner CE, et al. Extracellular signal-regulated kinase mediates phosphorylation of tropomyosin-1 to promote cytoskeleton remodeling in response to oxidative stress: impact on membrane blebbing. Mol Biol Cell. 2003;14(4):1418-32.

75. Varga AE, Stourman NV, Zheng Q, Safina AF, Quan L, Li X, et al. Silencing of the Tropomyosin-1 gene by DNA methylation alters tumor suppressor function of TGF- $\beta$. Oncogene. 2005;24(32):5043-52.

76. Bharadwaj S, Prasad G. Tropomyosin-1, a novel suppressor of cellular transformation is downregulated by promoter methylation in cancer cells. Cancer Lett. 2002;183(2):205-13.

77. Shields JM, Mehta H, Pruitt K, Der CJ. Opposing roles of the extracellular signal-regulated kinase and p38 mitogen-activated protein kinase cascades in Ras-mediated downregulation of tropomyosin. Mol Cell Biol. 2002;22(7):2304-17.

78. Shahrzad S, Bertrand K, Minhas K, Coomber B. Induction of DNA hypomethylation by tumor hypoxia. Epigenetics. 2007;2(2):119-25

79. Schevzov G, Whittaker SP, Fath T, Lin J, Gunning PW. Tropomyosin isoforms and reagents. Bioarchitecture. 2011;1(4):135-64.

80. Schevzov G, Vrhovski B, Bryce NS, Elmir S, Qiu MR, O'Neill GM, et al. Tissue-specific tropomyosin isoform composition. J Histochem Cytochem. 2005;53(5):557-70.

81. Nicholson-Flynn K, Hitchcock-DeGregori SE, Levitt P. Restricted expression of the actin-regulatory protein, tropomyosin, defines distinct boundaries, evaginating neuroepithelium, and choroid plexus forerunners during early CNS development. J Neurosci. 1996;16(21):6853-63.

82. Lynch J, Somerville T, Spencer GJ, Huang X, Somervaille TC. TTC5 is required to prevent apoptosis of acute myeloid leukemia stem cells. Cell Death Dis. 2013;4(4):e573. doi:10.1038/cddis.2013.107.

83. Shao H, Wang JH-C, Pollak MR, Wells A. a-actinin-4 is essential for maintaining the spreading, motility and contractility of fibroblasts. PLoS One. 2010;5(11), e13921.
84. Wong CC-L, Gilkes DM, Zhang H, Chen J, Wei H, Chaturvedi P, et al. Hypoxia-inducible factor 1 is a master regulator of breast cancer metastatic niche formation. Proc Natl Acad Sci U S A. 2011;108(39):16369-74.

85. Arzenani MK, Zade AE, Ming Y, Vijverberg SJ, Zhang Z, Khan Z, et al. Genomic DNA hypomethylation by histone deacetylase inhibition implicates DNMT1 nuclear dynamics. Mol Cell Biol. 2011;31(19):4119-28.

86. Gottipati P, Vischioni B, Schultz N, Solomons J, Bryant HE, Djureinovic T, et al. Poly (ADP-Ribose) polymerase is hyperactivated in homologous recombination-defective cells. Cancer Res. 2010;70(13):5389-98.

\section{Submit your next manuscript to BioMed Central and take full advantage of:}

- Convenient online submission

- Thorough peer review

- No space constraints or color figure charges

- Immediate publication on acceptance

- Inclusion in PubMed, CAS, Scopus and Google Scholar

- Research which is freely available for redistribution 